\title{
Impact of Thyristor Controlled Series Capacitor on Voltage Profile of Transmission Lines using PSAT
}

\author{
Babar Noor ${ }^{1}$, Muhammad Aamir Aman ${ }^{1}$, Murad Ali $^{1}$, Sanaullah Ahmad ${ }^{1}$, Fazal Wahab Karam. ${ }^{2}$ \\ Electrical Engineering Department, IQRA National University, Peshawar, Pakistan ${ }^{1}$, \\ Electrical Engineering Department, CIIT Abbottabad, Pakistan ${ }^{2}$
}

\begin{abstract}
In power system voltage stability is very important in order to maintain the voltage within the defined limits. The demand of electrical power increases in the last decade due to the lack of expansion in the generation and transmission network. The available transmission network is heavily loaded. This loading of transmission network cause the voltage instability. This instability on heavy loaded system creates voltage collapse which causes the power loss. Due to this phenomenon it is necessary to keep monitoring the voltage instability and to reduce voltage collapse. Voltage collapse mostly occurs due to the minimum availability of the reactive power. A power electronic device i.e. Flexible AC Transmission System (FACTS) is used to add the reactive power to the system which improve the voltage profile and minimizes the chances due to which the voltage collapse occur. In this paper FACTS series compensator, i.e. Thyristor Controlled Series Capacitors (TCSC) is injected between the two nodes of the IEEE 6 bus bar test system to check the voltage profile. PSAT (Power System Analysis Tool) tool, which is a new tool in MATLAB for study in power system analysis is used. IEEE-6 bus system is used as a test system for the effectiveness of the proposed method. The voltage profile with and without TCSC device is then compared to conclude the result.
\end{abstract}

Keywords-Flexible AC Transmission System (FACTS); Thyristor Controlled Series Capacitors (TCSC); Power System Analysis Tool (PSAT) tool; voltage profile; voltage collapse

\section{INTRODUCTION}

Power system is a vast and complex system in which large amount of generating units and substation are connected. The demand of power is increasing day by day and the system is overloaded because the system is already operated at its maximum capacity [1]. If contingency occur then the situation is not safe. These contingency or faults leads the system to voltage instability. Voltage instability happens in the system i.e. even a single disturbance fall the voltage down or rise to certain limits and at the end black outs and voltage collapse in the system occurs [2]. There is a gap between reactive power generation and demand, which causes problems in the voltage instability. Now a days two important factors are discussed in power transmission system, load and power quality. These relates to sudden increase in power demand to maintain the security of the system and a nonlinear load equipment such as machines and different electronics equipment's which are connected to transmission system. Due to the variation in the voltage profile, demand and generation causes voltage instability. This instability is due to the reactive power, which is unstable. Reactive power demand cannot be controlled because the load varies. To expand the transmission system it requires time, investment and right of way. Alternatively, FACTS device will be install instead of installing new transmission lines or replacement of transmission lines [3]. These devices are made from semiconductors, which are an ideal switch. FACTS devices are power electronic devices that are used to maintain operation of power system in a stable condition [4]. FACTS devices are used to solve many problems in power network and ensure secure operation of the power system. System flexibility is also provided by these devices. These devices improve the apparent power of the system that helps to enhance system operation and control over the system. SVC (Static Var Compensator), TCSC (Thyristor Controlled Series Capacitor), UPFC (Unified Power Flow Controller) and Static compensator, etc. are the several kinds of FACTS devices [5]. It is necessary to inject proper size FACTS device at optimal location because it causes voltage drop and too much heating due to huge amount of reactive power [2].

To prevent the system from voltage collapse, different methods for load flow analysis such as steady state analysis, continuation power flow method (CPF), optimal power flow $(\mathrm{OPF})$, etc. are used. Reactive power is very important in power system consisting of different transformers, circuit breakers, transmission, distribution lines and different types of loads having different power factor. Due to their intrinsic characteristics these devices shift the current and voltage measures in VARs. Due to change in the reactive power volt-ampere reactive (VAR) variation in the voltage profile occurs. If high amount of VARs injected to the system it increases losses in the system and decrease power transfer capabilities and when amount of VARs are low so it leads to voltage sag. To make a system in a stable position an appropriate amount of reactive power will be inject in a system. The compensation of reactive power improves voltage profile, transmission capability and control power flow to operate the system with flexibility [6].

This paper comprises of six sections. In first section the compensation of reactive power is explained. In second section FACT device is implemented in the system to check the disturbance in power flow mathematically. Third section explains TCSC FACT device and this device is implemented on the IEEE 6-bus test system to check the voltage profile. In the fourth section comparison is done with and without FACT device. Result and future work is explained in fifth and sixth section. 


\section{Compensation of Reactive Power}

The power network have a variable sending and receiving voltage due to the presence of different generation and utility appliances. These appliances have different magnitude and phase angles. If we want the voltage magnitude and phase at desire range between sender and receiver point or in stable position we have to compensate the system voltage. In order to compensate the system, different methods are used. For example, a capacitive load is add in parallel to produce reactive power that decrease the current drop in the line and voltage is improved. The second method to compensate a system is to install a compensator in the system that is use to mitigate voltage variations by controlling the reactive power automatically. These devices has the ability to inject or absorbed reactive power according to line requirement [7]. The equation of power flow in transmission line is shown as

$$
P=\frac{V_{s} V_{R}}{X} \sin \delta
$$

Where

$V_{s}$ and $V_{R}$ is sending and receiving voltages,

$\mathrm{X}$ is the impedance and $\delta$ is the power angle.

Now to increase power factor and reduce line impedance [7]. This power factor is increased by injecting the reactive power.

\section{FACTS DEVICES}

FACTS devices are used to improve power transfer capabilities and to improve system performance. These are solidstate devices consist of thyristor which do not contain any mechanical parts. It can be turn off and on with receiving signals. Different FACTS devices have multiple characteristics that are impedance, voltage and dynamic control of angle. The devices have very efficient control and quick response. Fig. 1 shows FACTS device injected between the sending and receiving end [7].

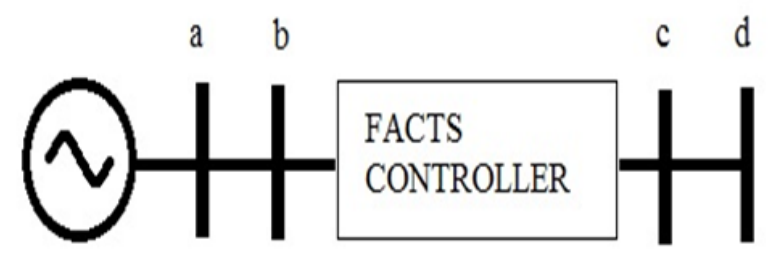

Sending End

\section{Receiving End}

Fig. 1. FACTS device injected between the sending and receiving end [7].

\section{FACTS Device and Disturbance in Power Flow}

Power flow and power quality is affected by the disturbance in the power system. The disturbances are usually voltage variation, transient instability and over voltages. These problems lead to overload the system and create power losses. Due to rapid increase in the population, the power demand is also increased. To cover the demand and supply gap, the generation must have to be increased but the capacity of existing transmission lines cannot be exceeded. As these transmission lines are overloaded and results in voltage reduction [8]. The possible solution of the problem is to extend the transmission lines capacity or to install new transmission lines to reduce the load on the existing transmission lines but the cost of transmission lines is very high. The alternative solution is to install FACTS device in our transmission system to prevent it from overloading condition and voltage collapse which causes the blackouts. This will also enhance the power quality, voltage stability and power transfer capability [3].

\section{Thyristor Controlled Series CAPACitor (TCSC)}

Thyristor Controlled Series Capacitor (TCSC) is a FACTS device connected in series on the transmission lines to control the dynamic power flow and enhance the power quality. It consists of thyristor, reactor and capacitors in which the thyristor is connected with a reactor that is in parallel to the capacitor along with the transmission line. TCSC control reactance due to reactors with shunt connected capacitor. This will increases the efficiency of transmission line. The capacitive reactance of the controller can be varied by varying the firing angle of the Thyristor Controlled Reactor (TCR). The load ability of the system is increased by decreasing the line effective reactance due to the capacitive reactance connected in series with the line reactance [7]. TCSC having a LC circuit carry constant current as shown in Fig. 2. The impedance is changing from maximum to minimum and increase the minimum capacitance while the arrangement of TCSC is such that the reactor $X_{C}$ is greater than the $X_{L}$ [9].

$$
X_{L}(\alpha)=X_{L} \frac{\pi}{\pi-2 \alpha-\sin 2 \alpha}
$$

Here

$X_{L}=$ Reactance of the Reactor

$\alpha=$ Firing Angle

TCSC is connected between the transmission line nodes "i" and "j" as shown in Fig. 3.

From power flow equations, the reactive and real power flow between nodes " $\mathrm{i}$ " and " $\mathrm{j}$ " is given as:

$$
P i j^{n}=V i^{2} G i j^{n}-V i V j\left(G i j^{n} \cos \delta_{i j}+B i j^{n} \sin \delta_{i j}\right.
$$

$Q i j^{n}=-V i^{2}\left(B i j^{n}+B_{s h}\right)-V_{i} V_{j}\left(G i j^{n} \sin \delta_{i j}-B i j^{n} \cos \delta_{i j}\right.$

And the flow of power between node $\mathrm{j}$ to node $\mathrm{i}$ is

$$
P j i^{n}=V i^{2} G i j^{n}-V i V j\left(G i j^{n} \cos \delta_{i j}+B i j^{n} \sin \delta_{i j}\right.
$$




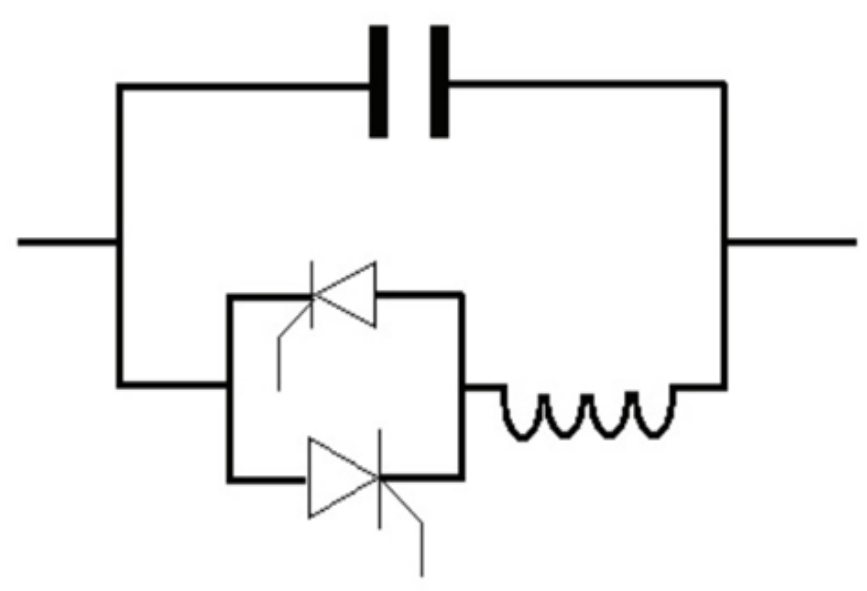

Fig. 2. Thyristor Controlled Series Capacitor (TCSC) [7].

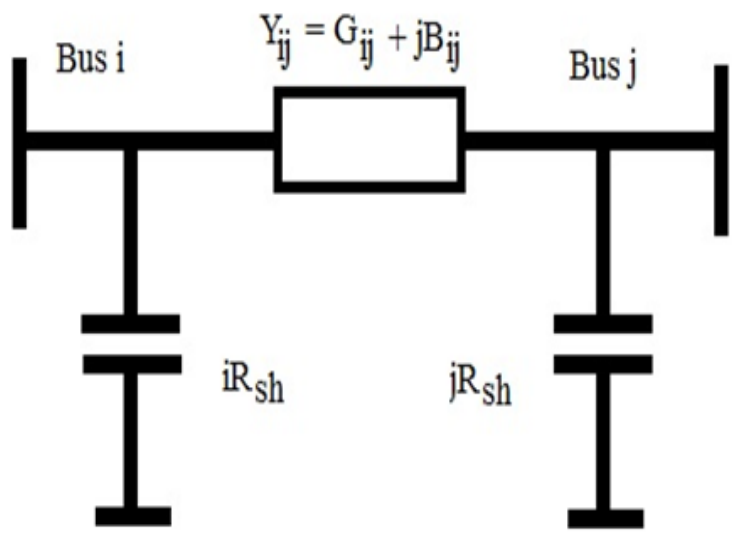

Fig. 3. Line representing between two buses [5].

$Q j i^{n}=-V i^{2}\left(B i j^{n}+B_{s h}\right)-V_{i} V_{j}\left(G i j^{n} \sin \delta_{i j}-B i j^{n} \cos \delta_{i j}[5]\right.$

Where, $\mathrm{G}$ is the conductance and $\mathrm{B}$ is the line susceptance.

\section{TCSC OPTIMAL LOCATION}

\section{A. Sensitivity Factors}

Sensitive lines are identified by sensitivity index based techniques to decrease reactive and active power loss and to improve voltage profile and stability by the placement of FACTS devices [5].

\section{B. Line Voltage Stability Index (LVSI)}

Voltage stability levels were predicted by using this LVSI values. These values will determine the weak transmission lines. Then according to their requirements these weak lines were provided proper amount of reactive power [5]. The line between the nodes " $\mathrm{i}$ " and " $\mathrm{j}$ " in the system is used to find the stability index of voltage.
LVSI is measured by the equation.

$$
L_{i j}-\frac{4 X Q}{\left(V_{i} \sin \left(\theta-\delta_{i j}\right)\right)^{2}}
$$

Where,

$L_{i j}$ represent the transmission line voltage stability index between node- $\mathrm{i}$ and node- $\mathrm{j}$

$\mathrm{Q}$ is the receiving end reactive power

$\mathrm{X}$ is the line reactance

$\theta$ is the line impedance

$V_{i}$ shows the sending end voltage

$\delta_{i j}=\delta_{i}-\delta_{j}, \delta_{i}$ and $\delta_{j}$ are the sending and receiving end angles of voltages.

When the line is stable, the value of line voltage stability index is always less than " 1 " [5].

\section{CASES}

The IEEE-6 standard bus system is considered as a test system with power base of $100 \mathrm{MVA}$ and frequency of $50 \mathrm{~Hz}$. The analysis of power flow is done by using Power system Analysis Toolbox (PSAT) which is a new toolbox of power system analysis in MATLAB. Newton Raphson method is used to determine the result. TCSC FACTs device will be install in the system between node 1 and 6 and then analyze the system. The comparison of both the results, i.e. with and without FACTS device will be investigated and impact on voltage profile will be analyzed. Fig. 4 shows IEEE-6 bus system modeled in PSAT without TCSC controller. Fig. 5 shows the TCSC FACTS device that is installed between bus 1 and 6 in IEEE-6 bus test system.

The load flow analysis of the system is analyzed. This analysis will show the voltage level at each bus and power flow across the network.

\section{A. System Parameters}

IEEE-6 Bus bars System Frequency $=50 \mathrm{~Hz}$ Base MVA $=100$ MVA Bus Voltage $=11 \mathrm{KV}$

\section{B. Line Data}

The line data is shown in Table I.

\section{Bus Data}

The bus data is shown in Table II. 


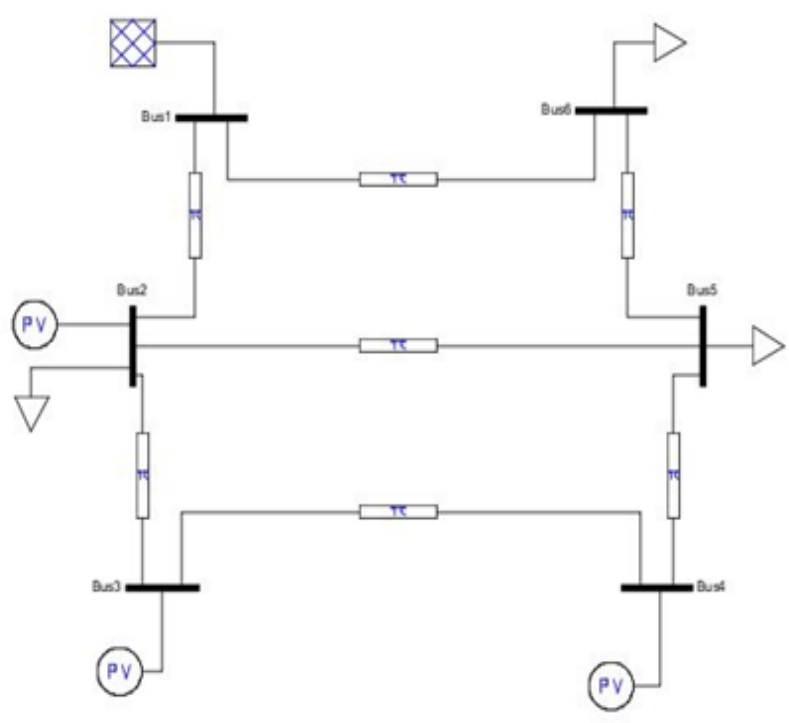

Fig. 4. IEEE 6-bus system without TCSC controller.

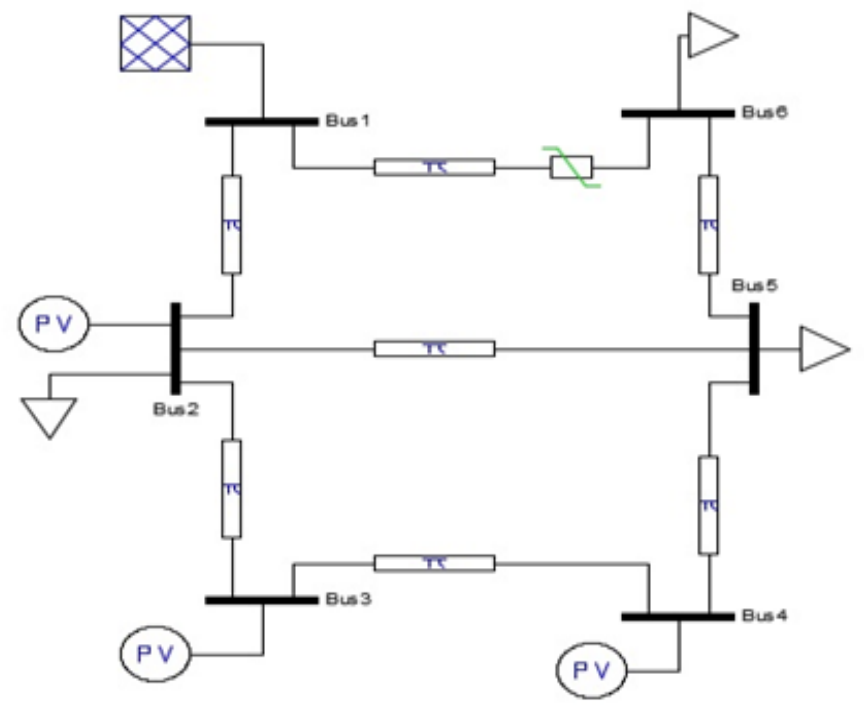

Fig. 5. IEEE 6-bus system with TCSC controller.

\section{TABLE I. LINE DATA}

\begin{tabular}{|c|c|c|c|}
\hline Lines & Buses & Resistance P.U & Reactance P.U \\
\hline \hline 1 & $1-2$ & 0.05 & 0.20 \\
\hline 2 & $2-3$ & 0.10 & 0.50 \\
\hline 3 & $3-4$ & 0.20 & 0.80 \\
\hline 4 & $4-5$ & 0.10 & 0.30 \\
\hline 5 & $5-6$ & 0.20 & 0.40 \\
\hline 6 & $6-1$ & 0.10 & 0.15 \\
\hline 7 & $2-5$ & 0.20 & 0.50 \\
\hline
\end{tabular}

TABLE II. GENERATION AND LOAD DATA

\begin{tabular}{|c|c|c|c|c|}
\hline \multirow{2}{*}{ Buses No } & \multicolumn{2}{|c|}{ Generation } & \multicolumn{2}{c|}{ Load } \\
\cline { 2 - 5 } & V P.u & MVA & MW & MVAR \\
\hline 1 & 1 & 100 & & \\
\hline 2 & 1.04 & 15 & 20 & 10 \\
\hline 3 & 1.04 & 40 & & \\
\hline 4 & 1.07 & 30 & & \\
\hline 5 & & & 40 & 15 \\
\hline 6 & & & 30 & 10 \\
\hline
\end{tabular}

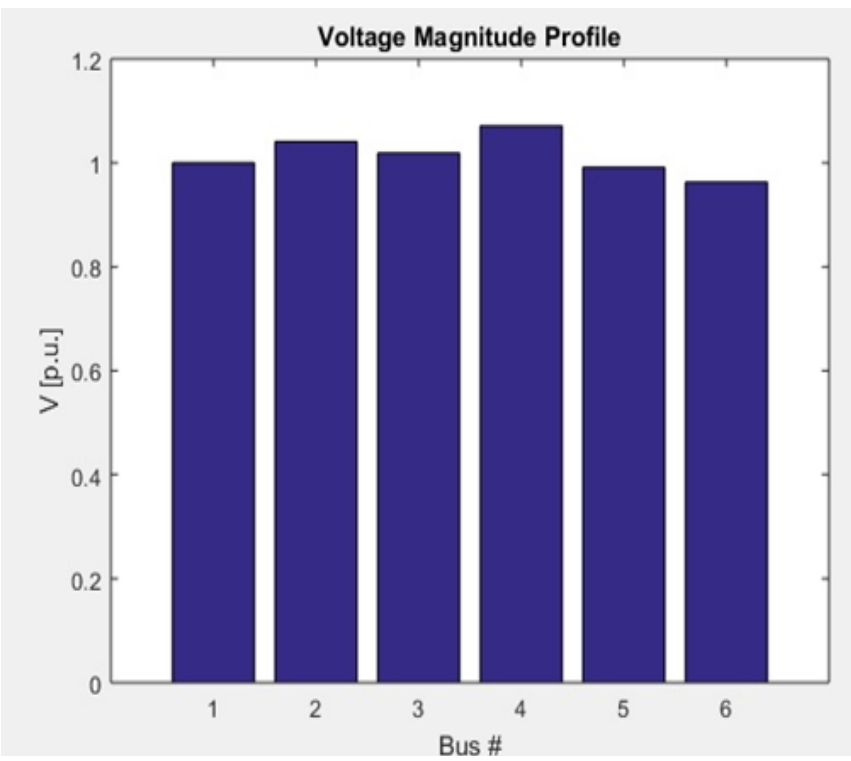

Fig. 6. Voltage profile of without TCSC controller.

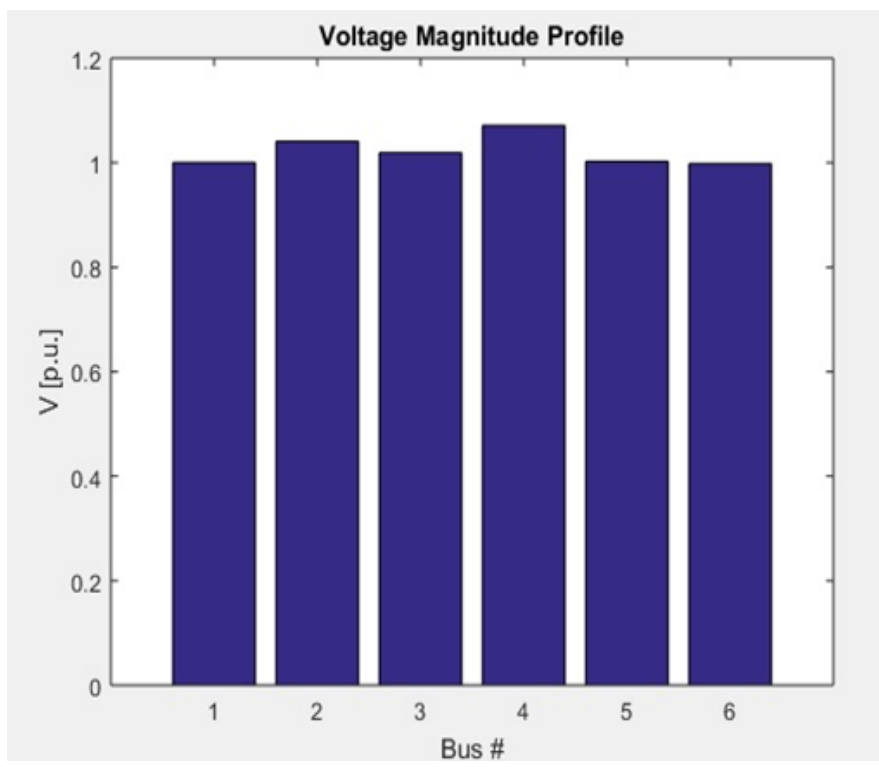

Fig. 7. Voltage profile with TCSC FACT device.

TABLE III. VOLTAGE COMPARISON With AND Without TCSC

\begin{tabular}{|c|c|c|}
\hline & Without TCSC & With TCSC \\
\hline \hline Bus 1 & 1 & 1 \\
\hline Bus 2 & 1.041 & 1.041 \\
\hline Bus 3 & 1.019 & 1.019 \\
\hline Bus 4 & 1.071 & 1.071 \\
\hline Bus 5 & 0.991363 & 1.002456 \\
\hline Bus 6 & 0.962995 & 0.998168 \\
\hline
\end{tabular}




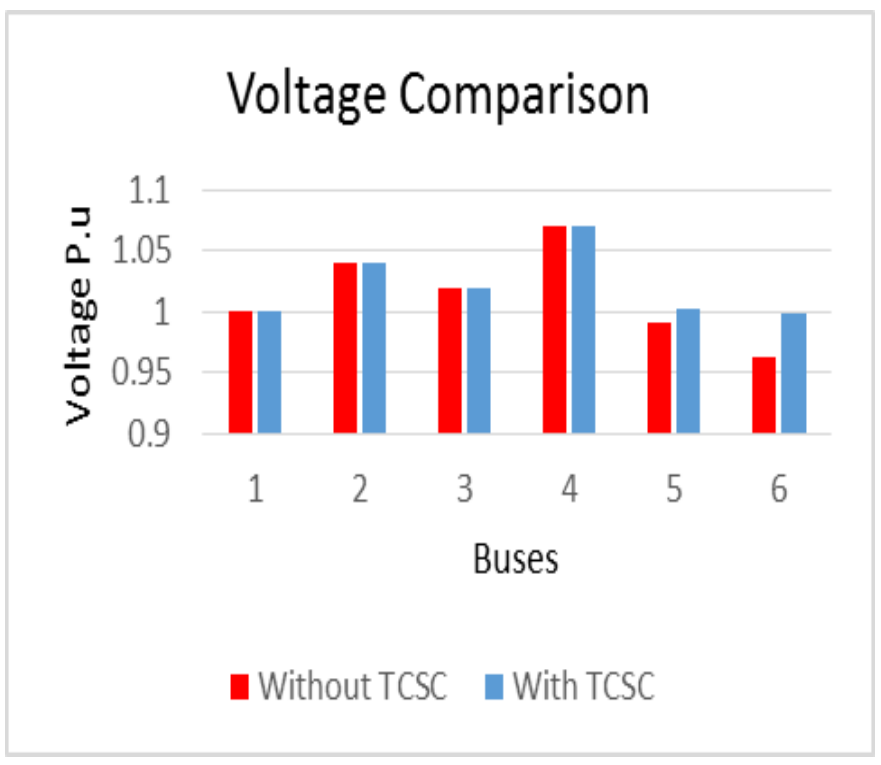

Fig. 8. Voltage comparison with and without TCSC device.

\section{RESUlTS AND DiscUSSION}

Fig. 6 shows the voltage magnitude of system without having TCSC device. Furthermore it was noticed that bus- 6 has lower voltage as compare to other buses and this bus is consider as a weak bus in case of any fault or overloading. TCSC FACTS device is installed between bus 1 and 6 for improving voltage profile. Fig. 7 shows the voltage magnitude after connecting FACTS controller. It is observed that the voltage magnitude enhances from 0.962 to 0.998 which shows that by connecting TCSC device the system voltage profile is improved. Fig. 8 shows the comparison between voltage magnitude i.e. Without TCSC installation and after connecting the TCSC device in the system. This comparison is then tabulated in Table III.

\section{CONClusion ANd Future Work}

In this paper the TCSC FACTS device is installed in the six bus bar IEEE test system and the voltage profile is analyzed using PSAT simulation tool. FACTS devices are used to improve the voltage profile of the network by injecting the reactive power to the system. Voltage level is analyzed at different buses and then identifies the weak voltage bus. The results are compared between the system without TCSC device and with TCSC device and concluded that by injecting the TCSC FACTS device between the node 1 and 6 of the IEEE- 6 bus test system, the voltage level improves which directly reduces the power loss. This work can be implemented with other IEEE test systems and also with comparison to other FACTS devices to check the feasibility. Also it can be implemented in between transmission or distribution line to reduce the losses and improve voltage.

\section{REFERENCES}

[1] M. A. Aman, S. Ahmad, and K. Mahmood, "Designing and strategic cost estimation of stand-alone hybrid renewable energy system," 2016.

[2] K. Hridya, V. Mini, R. Visakhan, and A. A. Kurian, "Analysis of voltage stability enhancement of a grid and loss reduction using series facts controllers," pp. 1-5, 2015.

[3] E. Yap, M. Al-Dabbagh, and P. Thum, "Applications of facts controller for improving power transmission capability," pp. 1-6, 2005.

[4] V. G. Mathad, B. F. Ronad, and S. H. Jangamshetti, "Review on comparison of facts controllers for power system stability enhancement," International Journal of Scientific and Research Publications, vol. 3, no. 3, pp. 2250-315, 2013.

[5] Y. Manganuri, P. Choudekar, D. Asija et al., "Optimal location of tesc using sensitivity and stability indices for reduction in losses and improving the voltage profile," pp. 1-4, 2016.

[6] J. Lakkireddy, R. Rastgoufard, I. Leevongwat, and P. Rastgoufard, "Steady state voltage stability enhancement using shunt and series facts devices," pp. $1-5,2015$.

[7] S. F. B. Shakil, N. Husain, M. D. Wasim, and S. Junaid, "Improving the voltage stability and performance of power networks using power electronics based facts controllers," pp. 1-6, 2014.

[8] M. A. Aman, S. Ahmad, A. ul Asar, and B. Noor, "Analyzing the diverse impacts of conventional distributed energy resources on distribution system," INTERNATIONAL JOURNAL OF ADVANCED COMPUTER SCIENCE AND APPLICATIONS, vol. 8, no. 10, pp. 390-396, 2017.

[9] V. Yarlagadda, D. B. S. Ram, and D. K. Rao, "Voltage stability improvement using thyristor controlled series capacitor (tcsc) based on $1 \mathrm{mn}$ and vcpi stability indices," International Journal Of Scientific \& Engineering Research, vol. 3, no. 4, 2012. 